\title{
BMJ Open Experiences of accessing and using breast cancer services in Vietnam: a descriptive qualitative study
}

\author{
Chris Jenkins (D) , ${ }^{1}$ Tran Thu Ngan, ${ }^{2}$ Nguyen Bao Ngoc (D) , ${ }^{2}$ Ho Thi Hien, ${ }^{2}$ \\ Nguyen Hoang Anh, ${ }^{3}$ Lynne Lohfeld, ${ }^{1}$ Michael Donnelly, ${ }^{1}$ Hoang Van Minh, ${ }^{2}$ \\ Liam Murray ${ }^{1}$
}

To cite: Jenkins C, Ngan TT, Ngoc NB, et al. Experiences of accessing and using breast cancer services in Vietnam: a descriptive qualitative study. BMJ Open 2020;10:e035173. doi:10.1136/ bmjopen-2019-035173

- Prepublication history and additional material for this paper are available online. To view these files, please visit the journal online (http://dx.doi. org/10.1136/bmjopen-2019035173).

LM since deceased.

CJ and TTN are joint first authors.

Received 22 October 2019 Revised 02 February 2020 Accepted 25 February 2020

Check for updates

(c) Author(s) (or their employer(s)) 2020. Re-use permitted under CC BY-NC. No commercial re-use. See rights and permissions. Published by BMJ.

${ }^{1}$ Centre for Public Health, Queen's University Belfast, Belfast, UK

${ }^{2}$ Centre for Population Sciences, Hanoi University of Public Health, Hanoi, Viet Nam

${ }^{3}$ Vietnam Women's Academy, Hanoi, Viet Nam

Correspondence to

Mr Chris Jenkins;

c.jenkins@qub.ac.uk

\section{ABSTRACT}

Objectives To understand, describe and analyse the experiences of women with breast cancer in Vietnam when accessing and using breast cancer services.

Design Descriptive qualitative study. Women were interviewed about their experiences from the first time they became aware of symptoms or changes to their body through treatment and post-treatment. This study is the first descriptive study on breast cancer in Vietnam from the perspective of women with a breast cancer diagnosis. Participants Women $(n=13)$ who had completed or were still receiving treatment for breast cancer, purposively recruited from the north and south of Vietnam.

Results An analysis of the experiences of women with breast cancer in Vietnam revealed a lack of awareness and knowledge about breast cancer and symptoms. Family and social support were described as key factors influencing whether a woman accesses and uses breast cancer services. Cost of treatment and out-of-pocket expenditures limited access to services and resulted in significant financial challenges for women and their families.

Conclusions Vietnam has made huge strides in improving cancer care, and is tackling a complex and expanding public health challenge, however, there are a number of areas requiring strengthening and future research. While Vietnam has successfully expanded social health insurance coverage, changes that increase the percentage of costs covered for specific treatments, such as chemotherapy or radiotherapy, could benefit women and their families.

\section{INTRODUCTION}

This study investigates the previously unexamined experience of women with breast cancer in Vietnam along different points of the diagnostic and treatment pathway. Data on cancer are limited with cancer registries being hospital based and datasets being partly based on mathematical models. ${ }^{1}$ Previous studies have, however, indicated increased challenges for Vietnamese society and the health system posed by non-communicable diseases, and particularly breast cancer given that it often is diagnosed in later stages. ${ }^{2-5}$ Breast cancer incidence is increasing steadily

\section{Strengths and limitations of this study}

- The study presents new and unique data on how breast cancer is conceptualised and the contextspecific challenges that women experience in accessing services in Vietnam.

- The international and interdisciplinary team have situated this study within a wider analysis of the Vietnamese health system, highlighting specific areas for further research and systems strengthening.

- Limitations include that it was not possible to conduct second interviews with three of the participants due to scheduling challenges and progression of disease and it is unknown whether the information they would have provided would have offered countering views to that of our other participants.

- Our participants were limited to Viet-speaking women enrolled as patients in the biomedical healthcare system, and so may not be representative of women not seeking care and/or ethnic minorities.

with an estimated 15229 new breast cancer cases annually and 6103 deaths. ${ }^{6}$

Research surveying and interviewing healthcare providers (HCPs) has indicated that there is a need for breast cancer systems strengthening across all levels of the Vietnamese health system and that lower levels of the health system often lack sufficient capacity to detect and diagnose breast cancer. ${ }^{7}$ The absence of qualitative data on breast cancer services from the perspective of women with a breast cancer diagnosis ${ }^{8}$ limits the effective planning of breast cancer services.

Studies from other low/middle-income countries (LMICs) on the needs and challenges of women with a breast cancer diagnosis have found fatalism, avoidance, lack of knowledge and lack of access to health services to be common barriers to timely diagnosis and treatment. Cultural attitudes towards health, decision making, women's roles and identity all contribute in varying degrees to late-stage diagnosis and difficulties 
in accessing and using treatment services. ${ }^{9-11}$ This study identified factors affecting women's experience of detection, diagnosis and treatment in Vietnam with the aim of increasing knowledge about barriers faced by women with breast cancer.

\section{METHODOLOGY}

This is a descriptive qualitative study ${ }^{12}{ }^{13}$ that aims to provide a comprehensive overview of the experience of women with breast cancer in Vietnam participating in the study. This guided the approach to sampling, data collection and analysis. Semi-structured in-depth interviews (see interview guides in online supplementary Information) were undertaken with 13 women with a breast cancer diagnosis in Vietnam. Two interviews were conducted with each woman, using the second interview to validate and deepen findings, enhance rigour and build trust between interviewers and participants. This was important given the highly sensitive content shared by the participants in this study. Second interviews took place approximately 2-3weeks following the first interview. Saturation was reached when initial thematic analysis indicated that comprehensive coverage of emergent themes was achieved, and in which researchers agreed that new information was unlikely to deepen the results. ${ }^{14} 15$ Informed consent was given by each participant. Interviews were conducted either at hospitals, the residences of women participating in our study, or convenient locations chosen by the women such as coffee shops.

The women who participated in our study were receiving or had received treatment for breast cancer in Hanoi or Ho Chi Minh City (HCMC), Vietnam. Women were recruited using a purposive sampling method through hospitals and support networks for cancer patients such as Chiến thắng ung thu (fight against cancer club) and Tinh thần-Thưc phẩm-Tập luyện-Thuốc (4T cancer club: mental resilience and support, diet and nutrition, exercise, and drugs and treatment). Support networks were identified through discussions with HCPs, key informants and online searches. Relationships with staff at hospitals and members of both clubs were developed throughout the 6 months prior to data collection, which facilitated recruitment for the study. Interviews were conducted by two female Vietnamese members of the research team in Vietnamese. All interviews were recorded and transcribed initially in Vietnamese. Two translators, selected for their expertise in social science research, produced verbatim English translations of each transcript.

\section{Patient and public involvement statement}

Women from breast cancer support networks both participated in the study and supported recruitment of additional participants. Women participating in the study presented their own stories and experiences at a dissemination conference in Hanoi with policy makers and key stakeholders. Women participating in the study have also been involved in subsequent work with the research team in developing arts-based approaches to increase knowledge and to reduce stigma associated with breast cancer.

\section{Data analysis}

Given the short time period between interviews and the multilingual make-up of the research team, designated team members carried out the initial analysis plus debriefing meetings immediately after each interview. This provided the opportunity to reflect on the information provided by each participant and for the non-Vietnamese researcher to ask questions of the two Vietnamese interviewers. As highlighted by McMahon and Winch, structured systematic debriefing helps strengthen collaborative global health qualitative research by enhancing quality and trustworthiness of data. ${ }^{16}$ Initial analysis allowed interviewers to reflect on and discuss interviewing style and technique, and promote reflection and discussion about other aspects of the interview such as tone of conversation, implied meanings of statements, emotion and body language. The results of these discussions informed the structure and content of personalised second interview guides. Detailed notes and audio recordings were taken during each debrief and used them to help ensure accuracy during analysis and write up.

Green and Thorogood highlight the importance of 'fully involving' translators and interpreters into studies, ensuring that they are part of the study team and not hired specifically as external translators. ${ }^{17}$ All transcripts were translated into English, and the translators were involved in the data analysis. This reduced the chance of translational and conceptual assumptions, improved clarity of meaning and provided opportunities to highlight nuances in how the women described their experiences. Given that "people communicate their meanings through language, (and that) words and language are the fundamental tools for creating and validating knowledge in qualitative research', ${ }^{18}$ significant time was allocated during the data analysis process to identify nuances in language and to attempt to collaboratively understand the meaning of the data collected.

Thematic analysis was informed by Fereday and MuirCochrane $^{19}$ who devised a hybrid model combining both data-driven (inductive) and theory-driven (deductive) approaches to qualitative thematic analyses. Their combination of data-driven and theory-driven coding supports the demonstration of rigour and credibility in qualitative research, enhancing the reading of the raw data by allowing for both a specific theoretical reading of the data as well as an inductive one.

The study was informed by a deductive approach using the pathways to treatment model. ${ }^{20}$ Scott identifies 'key time points' along the pathway that include the detection of bodily change, development of perceived reasons to consult with an HCP, first consultation with HCP, diagnosis and the start of treatment. Between each event are different processes and intervals. These include patient appraisal and self-management, decisions around helpseeking, processes of referrals and appointment making, 
and the scheduling of treatment. Contributing factors ranging from 'patient factors' (demographics, comorbidities, social and cultural determinants), health system factors (accessibility and service delivery) and disease factors (growth rate, site, size) all additionally impact on the pathway to treatment. Important caveats within the Scott model include the use of the term 'intervals' replacing the concept of 'delay' used in previous models by Anderson. Scott contends that 'not only is 'delay' value laden but it is also inaccurate as many patients seek help promptly'. ${ }^{20}$

This deductive approach informed and complemented an inductive reading of the data, highlighting additional and crosscutting themes emerging from the data. To ensure rigour, all transcripts were read multiple times, with key themes identified and discussed, and agreement reached regarding any differences within the analysis. Transcripts were analysed both individually (to understand the full experience of a single participant) and coded along different sub themes to understand trends across the study participants. Subthemes and codes were related to each of Scott's events, processes, intervals and contributing factors (eg, financial challenges, comments on the hospital environment, stigmatisation and so on). All data were inputted into tables by theme and subtheme and shared among the research team for further discussion.

\section{RESULTS}

A total of 13 women participated in the study who were either receiving, or had previously received, treatment services for breast cancer (table 1). Seven of the women were receiving or had received treatment in HCMC and six in Hanoi. All of women in Hanoi were in treatment at the time of our interviews. In HCMC, four out of seven were having treatment at the time of our interviews, while three women had completed treatment (within 5 years). Of the 13 participants, it was not possible to conduct a second interview with three women due to scheduling and logistical challenges (particularly women travelling long distances from rural areas for treatment) and progression of their breast cancer. It was not possible to travel to rural areas to conduct follow-up interviews due to logistical and financial constraints on the study.
Four themes were identified from the interviews: (1) a lack of knowledge and awareness about breast cancer, particularly for symptoms, which contributed to longer intervals in consulting an HCP, (2) misdiagnosis and poor communication with HCPs, (3) the impact and experience of economic pressure created by diagnosis and treatment and (4) the importance of networks, gender roles and norms.

Women diagnosed in the earlier stages (one and two) $(\mathrm{n}=8)$, compared with the later group (three and four) $(n=4)$ (one woman unknown stage of diagnosis), had greater uptake of annual health checks, normally provided for by their employers. None of the women diagnosed at later stages regularly attended health check-ups (either privately, company provided or part of screening campaigns) prior to their diagnosis. All the participants sought and received biomedical treatment. None of the participants had abandoned treatment, although one woman interrupted her treatment to use traditional medicine in isolation. All women described having either full or partial access to surgery, chemotherapy and hormone therapy, and four women reported receiving radiotherapy. Analysis of findings revealed no major differences by geography (north/south), with the exception of women in the south of Vietnam having greater access to support networks and patient groups.

\section{Lack of awareness and knowledge}

Participants described a lack of knowledge about breast cancer symptoms and treatment options prior to their diagnosis. None of the women had extensive knowledge of breast cancer symptoms prior to diagnosis (eg, such as dimpling, discharge from nipples, lumps or swelling in armpits). While nearly every participant described the discovery of a lump as the initial moment of realisation of a potential problem, many did not equate this discovery to something that required immediate action:

I did not have the knowledge. I thought it was only dangerous when it hurt. In the countryside, people rarely go to see the doctor. (P4: rural residence; diagnosed stage 3 )

The bodily change detected by each woman was a breast lump, often discovered when bathing. Later symptoms included pain, nausea or fainting. Women waited as long as 5 months (P12) before deciding they needed to speak

Table 1 Participant information

\begin{tabular}{|c|c|c|c|c|c|c|c|}
\hline \multicolumn{8}{|c|}{ Participants $(n=13)$} \\
\hline \multicolumn{2}{|c|}{ Age (years) } & \multicolumn{2}{|c|}{ Residence } & \multicolumn{2}{|l|}{ Marital status } & \multicolumn{2}{|c|}{ Stage of diagnosis } \\
\hline 25-39 & 6 & Urban & 6 & Married & 9 & Stage 1 & 1 \\
\hline $55-69$ & 3 & Rural $=$ & m city limits & Widowed & 1 & Stage 3 & 3 \\
\hline Missing & 2 & & & & & Stage 4 & 1 \\
\hline
\end{tabular}


to an HCP. None of the women equated the discovery of a lump to an immediate belief that it could be breast cancer and were not concerned because the lump was not painful to the touch:

I was fine, I didn't feel any pain. So I didn't go for a health check. When I went for a health check, I had the disease and everyone was surprised. (P12: rural residence; diagnosed stage 2 )

None of the women had been exposed to any in-depth public health messages about breast cancer and only one woman knew how to conduct a breast self-examination. Most women accessed information online but did not trust their information sources:

When I need something (information) I just searched for it on the internet. I do not know which sources are reliable. (P8: urban residence; diagnosed stage 4)

None of the women diagnosed at later stages (3 and 4) had ever been (or in some cases heard of) breast cancer screening. No women detected a change to their breast through an organised screening programme and only one woman reported having regular (annual) mammograms. Even women who reported attending regular private check-ups or having company-provided check-ups $(n=4)$ indicated a lack of concern and awareness around breast health prior to their diagnosis. This was particularly striking when compared with much wider levels of knowledge concerning cervical cancer and prevention through screening:

I only ever focused on the 'bottom part' of my body. Information about breast cancer is scarce. People usually do not think you can get cancer there. I only started to know about the disease after I got it. (P2: rural residence; diagnosed stage 3)

Confirmation of a breast cancer diagnosis was often described as a moment of shock, fear and panic. Many women explained that in Vietnam people often equate a cancer diagnosis with death. This view was not held by any of our participants, possibly because they all had completed or were still undergoing biomedical treatment for their cancer:

In my hometown, when people hear 'cancer' they think $100 \%$ you will die, there is no way you could live. Some say it costs too much and you will die anyway. You do not get any better so why do you keep doing that (traveling and paying)? (P4: rural residence; diagnosed stage 3)

Only one participant $(\mathrm{P} 7)$ described traditional or alternative sources of care as able to cure cancer. Other women in the study described that beliefs in the curative power of traditional medicines were prevalent in their communities. For the most part, however, most women described a commitment and belief in biomedical approaches to treatment:
I always reinforced my thought that I will follow Western medicine. I went to the hospital for a health check. My family advised me to use the herb but I was determined to follow Western medicine. I know many people who used traditional medicine but could not treat their disease. Then when they went to the hospital the disease was in the severe stage. It could not be cured anymore. (P13: urban residence; diagnosed stage 2)

\section{Experiences of misdiagnosis and poor communication with HCPs}

Where women entered the health system varied, with some initially attending their local commune health station (primary, preventative health centres) with others going directly to National and Provincial Oncology hospitals. Regardless of the level in which the women entered, however, the women in our study described processes of missed diagnosis, multiple referral and confusion over their diagnosis:

The doctors did not diagnose a tumor. They said everything was okay. (P6: urban residence; diagnosed stage 2)

Seven women explicitly described receiving an incorrect diagnosis or incorrect information about their diagnosis or referral. In every case, this misdiagnosis was for something less severe than breast cancer such as fibroid breast tumours, carpal tunnel (in the arm) and benign tumours. The interval between the first consultation with an HCP and a confirmed diagnosis often required multiple tests, frequently carried out at different hospitals, with a lack of information or support for women to navigate the process.

In the first test they concluded that the lump was benign, but when I took the test again, it was cancer. (P9: rural residence; diagnosed stage 2)

A lack of information about the formal referral pathways and possible treatment routes was evident for most of the women in our study. First contact with HCPs tended to be short and not accompanied by support or information. This trend was replicated throughout the treatment pathway at all levels and these experiences are reflective generally of the lack of streamlined protocols in place to assist in receiving a confirmed diagnosis:

Procedures at hospitals are very complicated, so patients cannot feel at ease. I am lucky because I have my husband but most people come alone, and they have to go to this place and do things, they have to go out and make photocopies, they have to go to that place to submit and they have to come back again. It is like they are being chased. As long as the procedures are complicated patients can never feel at ease. (P4: rural residence; diagnosed stage 3) 
The processes of confirming a final diagnosis were described as confusing, and often with little information provided by HCPs. One woman did not know what stage of cancer she had at diagnosis. Many participants described a lack of clarity on what their diagnosis meant:

If you asked too many questions, they would scold you. You can't blame them though because there are too many patients at the Oncology hospital. (P3; rural residence; stage of diagnosis unknown)

Additionally, some of the women described tests they were given to confirm breast cancer as being traumatic, for example surgical biopsies being conducted without anaesthesia:

It would hurt to death. No anaesthesia. They would make an incision and then a machine would close it.

(P1: urban residence; diagnosed stage 2)

One woman (P3) described asking her family not to visit because of the conditions in the hospital. Almost all of the women focused their discussion of treatment on overcrowding in the hospitals and the associated lack of contact and information that HCPs were able to provide. Hospital wards were described as overcrowded, often with women sharing a bed or lying on the floor, women receiving chemotherapy while sitting on chairs and patients lying in corridors:

It's overcrowded. Overloaded. In that room, there must be 3 or 4 people sharing a bed. They need to borrow beds and lie outside. (P9: rural residence; diagnosed stage 2)

The difficult conditions and low physician/patient ratio make it very difficult for HCPs to effectively manage individual patients or communicate clearly with women and their families:

I want the doctors to be more dedicated, which means they should give me more advice on the stage of my disease, or which medication I need to buy or what I should do. Now they only answer what I ask. They don't actively consult me about which medicines I should and shouldn't use. They don't explain it to me in detail. (P8: urban residence: diagnosed stage 4)

A number of women were critical of facilities at the lower levels of the health system, with inaccurate diagnoses and insufficient information from providers. Many women therefore would bypass lower levels of the system if they had the capacity and resources to do so:

If only lower levels hospitals were good at treating patients and could detect diseases, people would be so lucky. It would cost less, it would take less time, and it would be more effective for the patients. (P2: rural residence; diagnosed stage 3 )

Proactive HCPs were crucial in the stories of two participants, encouraging them to seek further examinations and diagnosis, and providing support during treatments.
It should be emphasised that many women recognised that often HCPs were doing their best to provide support, but that they did not have time and the necessary training to meet patients' needs.

\section{Economic pressures created by diagnosis and treatment}

Economic factors were discussed at length by participants in the study. Our study population came from varied socioeconomic backgrounds. Some women had insurance before their diagnosis, whereas others acquired insurance during treatment or held certificates of the poor and near-poor which allowed them to access subsidised or free health services. For those paying for treatment (those without certificates of the poor), overall self-reported direct costs ranged from 300 to 700 million VND (US\$13000-US\$35000) not covered by insurance. For surgery, most women paid between 20 and 30 million VND (US\$1000), while chemotherapy was often described as being anything up to 30 million VND per session:

30 million per week, not to mention food costs and other medicines. Not to mention pain relievers, supplement infusion, this and that costs. That is only for the chemicals. Also the money on commuting. You have to spend millions per hour during a hospital visit. People with money think about dying because of the disease. People without money think about dying because of not having money. (P1: urban residence; diagnosed stage 2)

The lack of streamlined or standardised price points is a clear problem, with many women stating they did not understand what the costs were going to be before they started treatment. Insurance coverage was reported as covering $80 \%$ of costs for surgery and $50 \%$ for chemotherapy, however, there were variations and generally information around exact costs was opaque. A number of women described needing to sell possessions and houses in order to pay for the costs of treatment, as well as taking loans and entering into debt:

If you have a house then you can sell your house, but if you don't then what can you sell to get money for treatments? That is the problem. It is the same in every hospital in the country. ( $\mathrm{P} 4$ : rural residence; diagnosed stage 3)

Women at the lowest socioeconomic levels but without government support reported that treatment costs were oppressive. Even women with certificates of the poor and near-poor faced significant problems in covering out-ofpocket expenditure.

Some women described feeling despair and hopelessness during the time between receiving a firm diagnosis and beginning treatment. The combination of fatalistic views and costs of treatment meant some women questioned the value of spending money on treatment:

Many people got hopeless and did not go to the hospital to be treated. There are also people who said 
they did not have money and even if they were treated it's not going to work. (P7: urban residence; diagnosed stage 1)

\section{The importance of support networks, family, gender roles and} norms

Women from rural backgrounds and without family or ties to large cities faced particular challenges in terms of accessing centralised oncology services, especially when trying to schedule appointments, cope with long waiting times and courses of treatments such as chemotherapy. Many women from rural areas mentioned additional costs they bore, such as when renting accommodation near the hospitals.

The role of women, gender norms and the importance of support networks were commonly expressed by participants. Five women reported they delayed seeking a diagnosis from a biomedical professional for a significant amount of time (2-5 months) citing work and family commitments as a bigger concern and priority than concerns over their health. Stoicism and sacrifice were subthemes described throughout the study. One woman described ignoring her initial symptoms because she had to care for other unwell members of her family while continuing to earn money:

I said jokingly (to my husband) that if I feel sick too we were going to starve to death, because in the countryside you have to work every day for food you know.

(P4: rural residence; diagnosed stage 3)

For many women, having a supportive partner or family to encourage them to seek professional healthcare advice and services was a central factor reducing the time between detecting a change and deciding to consult an HCP or actually seeking a consultation. The importance of supportive family was echoed throughout the narratives of women participating in our study across all events, intervals and processes along the pathway to treatment:

My husband's family and my husband are very supportive. That is my motivation to fight back with this disease. (P13: urban residence; diagnosed stage 2)

In some cases supportive networks extended beyond the immediate family to other friends or workmates. Some women cited the importance of having supportive HCPs to encourage them to seek a formal examination and diagnosis, as well as helping them to understand and acquire insurance.

Older participants said they felt that breast cancer would be particularly difficult for younger women with partners. Three of the women in our study were separated from their husbands, and all three indicated that their diagnosis played a role in their separation. Relationship breakdown was discussed as being frequent among other women outside the study, with women citing both economic and aesthetic reasons:
My husband left me. I have to manage myself. When I woke up, he was gone. (P12: rural residence; diagnosed stage 2)

\section{DISCUSSION}

Women across the study reported a lack of awareness of symptoms of breast cancer; delay in speaking to an HCP; fear, shock and the belief that cancer is incurable; and fear of the pain and long-term impact on the body due to treatment. These experiences are reflective of much of the international literature on breast health in LMICs. ${ }^{112122}$ The association between cancer and death, and the resultant fear of being diagnosed with the disease is a dominant emotional reaction across multiple studies in different contexts. ${ }^{23}$ Fears are also linked to pain, treatment and physical changes associated with having cancer. Fear (not lack of knowledge about symptoms, but a lack of knowledge that breast cancer is treatable) was directly linked by women in two studies to their decision to delay seeking medical diagnosis. ${ }^{10}{ }^{25}$ Equally, social challenges described by women in this study in relation to social stigma, breakdown of intimate relationships, social isolation and role weakening have been well documented by studies in other LMICs. ${ }^{1024} 26-28$

In this study, women also spoke about fearing the financial implications of undergoing treatment. Cancer patients and their families experience economic stress globally. In Vietnam, however, these challenges appear particularly pronounced. Women in our study described significant out-of-pocket and direct costs for their treatment, and explicitly referenced their fear of costs: 'I was afraid I could not afford it... I was not afraid of dying' (P2). Although Vietnam has a high (and steadily increasing) rate of coverage of insurance-now reported at $87 \%$ of the population-plus special coverage for the poor and near-poor, health costs are often catastrophic. Women in this study reported selling possessions including their homes, delaying treatment due to lack of finances and the emotional and financial stress on the family unit of having to pay for treatment. Self-reported direct costs ranged from 300 to 700 million VND. Older studies have estimated less catastrophic costs for breast cancer treatment. For example, Hoang Lan et al estimated the average 5-year treatment costs for breast cancer to be S\$975 (22 million VND, 2019). Hoang Lan et al did not account for out-of-pocket expenditure, whereas many women in this study discussed both direct and indirect costs (bureaucratic and administrative costs, accommodation, food and travel). Even accounting for out-of-pocket expenditure, inflation, some of the women in the study paying for semi-private rooms, and the improving Vietnamese economy, it is unclear why there is such high variation in reported costs between these studies. Wider costing studies should therefore be undertaken.

Prior research in Vietnam shows that levels of financial catastrophe (when health costs $>40 \%$ of the household's 
capacity to pay) and impoverishment (when a non-poor household is impoverished by healthcare costs) ${ }^{29}$ from healthcare costs are high in Vietnam. One study estimated that in 2013, 862661 and 563785 households across Vietnam were pushed into financial catastrophe and impoverishment, respectively, when faced with the costs of a serious health problem. ${ }^{30}$ At particular risk were older adults and/or people living in rural or lower socioeconomic status households. Another study on the financial burden on households paying for cancer treatment reported that $37.4 \%$ of the households within the study $(\mathrm{n}=1141)$ had been impoverished due to the high cost of treating cancer. ${ }^{31}$

A number of services, such as surgery and chemotherapy, are only partially covered by insurance. And other services such as screening and mammography are currently not covered under the social health insurance model. It is likely that there are large numbers of households in Vietnam that cannot afford cancer treatment even if they have insurance. Such barriers must be addressed, such as continuing the push to achieve Universal Health Coverage-a goal the Vietnamese government has been striving for and towards which it is making significant progress, while also considering increasing the levels of coverage for certain treatments like chemotherapy and radiotherapy. A full costing study would be necessary to ascertain the feasibility of this approach.

Population or targeted screening campaigns remain limited, and none of the women in our study entered the health system through a screening programme. While there have been a number of one-off screening campaigns $^{8}$ and different organisations such as the Bright Future Foundation have recently funded and purchased a breast cancer screening bus, this service remains largely inaccessible for many women. Interestingly, more women seemed to be aware of screening services for cervical cancer, and this may represent a model of good practice from which to build on.

The finding that none of the women in our study entered services through community-based screening may be reflective of wider systemic challenges in services delivery at lower levels of the health system. A lack of confidence among women in the responsiveness and effectiveness of lower levels of the health system may lead women to travel to centralised healthcare facilities to access services. This pathway tends to increase their outof-pocket expenditure and contributes to overcrowding in central facilities while also creating challenges for HCPs in terms of providing the necessary care, consultation and information that women and their families require. It is likely also that limited provision and delivery of services at lower levels of the healthcare system also likely contributes to health inequalities between rural and urban areas.

Significant challenges remain for women in Vietnam in relation to stigmatisation of breast cancer. Interventions that seek to challenge traditional narratives of disease causation, as well as challenging narratives surrounding gender politics, the role of women and confronting the aesthetic impacts of breast cancer treatment may be useful. Stoicism and the expectation for women to sacrifice their own health for family members were widely described, and could be addressed through targeted interventions. Many women described directly or indirectly the theme of relationship breakdown postdiagnosis. Given the importance of a strong support network for women when navigating oncology services, campaigns that explore role modelling showing supportive male behaviours and relationships may be beneficial.

\section{LIMITATIONS}

It was not possible to conduct second interviews with three of the participants due to scheduling challenges and progression of disease. It is unknown whether the information they would have provided would have offered countering views to that of our other participants. Our participants were limited to Viet-speaking women enrolled as patients in the biomedical healthcare system, and so may not be representative of women not seeking care and/or ethnic minorities. Many of the economic figures provided by the participants such as for treatment and out-of-pocket costs, should be considered as broad estimations. As with any figures generated from memory, caution should be used when interpreting their accuracy and significance. Nonetheless, the clear message from our participants that a diagnosis of cancer brings for many households the risk of financial challenges echoes findings from other recent studies in Vietnam.

\section{CONCLUSIONS}

This paper has highlighted significant challenges for women with breast cancer in Vietnam, including lack of knowledge, economic challenges and negative experiences of using breast cancer services. Cancer control and treatment in Vietnam have improved dramatically in the last two decades, but further work is required to increase and support women to access and use breast cancer services at early stages of disease. This may include increasing financial support for women with breast cancer through increasing insurance coverage for different treatments. Other factors such as social stigma, lack of support systems and misdiagnosis along the patient pathway were consistent findings that should be addressed with focused interventions and further research.

\section{Twitter Chris Jenkins @ChrisJenkins90}

Acknowledgements We would like to thank the Hanoi Oncology Hospital and the cancer support networks Chiến thắng ung thư and Tinh thần-Thực phẩm-Tập luyện-Thuốc for their support in recruiting women for this study. We would also like to sincerely thank all the women in our study for giving their time, sharing their experiences, inviting us into their homes, giving us presents and bringing us bread and cake. It was a privilege to hear your stories, meet you, and we hope this paper is the best possible reflection of the experiences you have shared with us. The authors would like to acknowledge the significant contribution of Professor Liam Murray to this project and to recent collaborative cancer research efforts in Vietnam. Liam established the research collaboration between Queen's University Belfast and the Hanoi University of Public Health, and he was central in leading 
the formation and development of this project. In January 2018, Liam sadly and prematurely died from pancreatic cancer.

Contributors CJ (Research Assistant at Queen's University Belfast) and TTN (Research Assistant at Hanoi University of Public Health) led the development and implementation of the study. CJ developed interview guides, and led analysis and writing of the paper. TTN led all interviews with support from NBN. NHA supported recruitment, shaped the conceptual design of the paper, and contributed to analysis. HTH, LL and MD supervised the production of the paper, contributing to the methodological development of the study and training of lead researchers. HVM and LM oversaw the development of the research partnership between the Hanoi University of Public Health and Queen's University Belfast, leading the development of a programme of breast cancer research and contributing to the conceptual design of all studies. MD served as the QUB caretaker PI following the untimely passing of LM. All authors, with the exception of LM (for reasons outlined in the acknowledgements), read, commented upon and contributed to the drafting of the paper.

Funding This work was supported by a British Council Newton Grant (Institutional Links) under Grant number: 216383378. The project was additionally supported through a Global Challenges Research Fund (GCRF) (Department for Economy) Grant, DFEGCRF-21.

Competing interests None declared.

Patient consent for publication Not required.

Ethics approval This study received ethical clearance from Institutional Review Board of Hanoi University of Public Health in Vietnam. No. 017-373/DD-YTCC. All participants in the study provided written consent, and were fully informed about how their information would be used. Given the sensitive content within this study, we ensured that a trained counsellor would be available should any participant desire confidential professional support. All the women were informed of this option should they require it, but none requested it.

Provenance and peer review Not commissioned; externally peer reviewed.

Data availability statement All data relevant to the study are included in the article or uploaded as supplementary information. Additional protocols are available upon request.

Open access This is an open access article distributed in accordance with the Creative Commons Attribution Non Commercial (CC BY-NC 4.0) license, which permits others to distribute, remix, adapt, build upon this work non-commercially, and license their derivative works on different terms, provided the original work is properly cited, appropriate credit is given, any changes made indicated, and the use is non-commercial. See: http://creativecommons.org/licenses/by-nc/4.0/.

\section{ORCID iDs}

Chris Jenkins http://orcid.org/0000-0003-3514-3581

Nguyen Bao Ngoc http://orcid.org/0000-0002-0316-7450

\section{REFERENCES}

1 Pham T, Bui L, Kim G, et al. Cancers in Vietnam-Burden and control efforts: a narrative scoping review. Cancer Control 2019;26:107327481986380.

2 Lan N, Laohasiriwong W, Stewart J. Survival probability and prognostic factors for breast cancer patients in Vietnam. Glob Health Action 2013;6:18860-9.

3 Hoang Lan N, Laohasiriwong W, Stewart JF, et al. Cost of treatment for breast cancer in central Vietnam. Glob Health Action 2013;6:18872

4 Thuan TV, Anh PT, DV T. Cancer control in Vietnam. where are we? Cancer Control, 2016. www.cancercontrolinfo;

5 Trieu PDY, Mello-Thoms C, Brennan PC. Female breast cancer in Vietnam: a comparison across Asian specific regions. Cancer Biol Med 2015;12:238-45.
6 GLOBOCAN. Population Factsheet: Vietnam, 2018. Available: https:// gco.iarc.fr/today/data/factsheets/populations/704-viet-nam-factsheets.pdf

7 Jenkins C, Ngan TT, Ngoc NB, et al. Strengthening breast cancer services in Vietnam: a mixed-methods study. Glob Health Res Policy 2019;4:2

8 Jenkins C, Minh LN, Anh TT, et al. Breast cancer services in Vietnam: a scoping review. Glob Health Action 2018;11:1435344.

9 Barthakur MS, Sharma MP, Chaturvedi SK, et al. Experiences of breast cancer survivors with oncology settings in urban India: qualitative findings. Indian J Surg Oncol 2016;7:392-6.

10 Hajian S, Mehrabi E, Simbar M, et al. Coping strategies and experiences in women with a primary breast cancer diagnosis. Asian Pac J Cancer Prev 2017;18:215-24.

11 Xiong M, Stone TE, Turale S, et al. Women's experiences of making healthcare decisions about their breast cancer: a phenomenological study. Nurs Health Sci 2016;18:314-20.

12 Sandelowski M. What's in a name? qualitative description revisited. Res Nurs Health 2010;33:77-84.

13 Sandelowski M. Whatever happened to qualitative description? Res Nurs Health 2000;23:334-40.

14 Saunders B, Sim J, Kingstone T, et al. Saturation in qualitative research: exploring its conceptualization and operationalization. Qual Quant 2018;52:1893-907.

15 Corbin J, Strauss A. Basics of qualitative research: techniques and procedures for developing Grounded theory. California: Sage Publications, 2015

16 McMahon SA, Winch PJ. Systematic Debriefing after qualitative encounters: an essential analysis step in applied qualitative research. BMJ Glob Health 2018;3:e000837.

17 Green J, Thorogood N. Qualitative methods for health research. 2nd ed. London: Sage, 2009.

18 Taylor B, Francis K. Qualitative research in health sciences: methodologies, methods and processes. Routledge, 2013.

19 Fereday J, Muir-Cochrane E. Demonstrating rigor using thematic analysis: a hybrid approach of inductive and deductive coding and theme development. Int J Qual Methods 2006;5:80-92.

20 Scott SE, Walter FM, Webster A, et al. The model of pathways to treatment: conceptualization and integration with existing theory. $\mathrm{Br} \mathrm{J}$ Health Psychol 2013;18:45-65.

21 Liamputtong P, Suwankhong D. Living with breast cancer: the experiences and meaning-making among women in southern Thailand. Eur J Cancer Care 2016;25:371-80.

22 Mehrabi E, Hajian S, Simbar M, et al. Post-Traumatic growth: a qualitative analysis of experiences regarding positive psychological changes among Iranian women with breast cancer. Electron Physician 2015;7:1239-46.

23 Obeidat RF, Dickerson SS, Homish GG, et al. Controlling fear: Jordanian women's perceptions of the diagnosis and surgical treatment of early-stage breast cancer. Cancer Nurs 2013;36:484-92.

24 Shrestha K. Psychological impact after mastectomy among Nepalese women: a qualitative study. Nepal Med Coll J 2012;14:153-6.

25 Demir F, Donmez YC, Ozsaker E, et al. Patients' lived experiences of excisional breast biopsy: a phenomenological study. J Clin Nurs 2008;17:744-51.

26 Inan Figen Șengün, Günüșen NP, Üstün B. Experiences of newly diagnosed breast cancer patients in turkey. J Transcult Nurs 2016;27:262-9.

27 Joulaee A, Joolaee S, Kadivar M, et al. Living with breast cancer: Iranian women's lived experiences. Int Nurs Rev 2012;59:362-8.

28 Lam WWT, Fielding R. The evolving experience of illness for Chinese women with breast cancer: a qualitative study. Psychooncology 2003;12:127-40.

29 WHO. Distribution of health payments and catastrophic expenditures methodology. WHO, 2005.

30 Partnership for Action in Health Equity. The 2nd Vietnam health Watch report: health system in Vietnam: towards targets with equity. Workers' Publishing House, 2013.

31 Hoang VM, Pham CP, Vu QM, Minh H, Phuong Pham C, Mai Vu Q, et al. Household financial burden and poverty impacts of cancer treatment in Vietnam. Biomed Res Int 2017;2017:1-8. 